\title{
The influence of bracket torque on external apical root resorption in bimaxillary protrusion patients: a retrospective study
}

\author{
Xiaojuan Zhang ${ }^{1^{*}}$, Hong Zhou ${ }^{2}$, Xiangling Liao ${ }^{1}$ and Yi Liü ${ }^{3^{*}}$
}

\begin{abstract}
Background: To evaluate the difference in root resorption between standard torque self-ligating brackets and high torque self-ligating brackets in bimaxillary protrusion patients after orthodontic treatment.

Methods: Pre-treatment and post-treatment Cone beam computed tomography (CBCT) of 32 patients (16 treated with the high torque DamonQ $0.022^{\prime \prime}$ bracket and 16 with the $0.022^{\prime \prime}$ standard torque self-ligating bracket) were selected. The first premolars were extracted from all patients before treatment. After mini-screw implants were inserted into the buccal region between the second premolar and first molar, $150 \mathrm{~g}$ of force was applied to retract the upper and lower anterior teeth to close the extraction space on each side. CBCT images of all patients were taken before and after treatment. Three-dimensional reconstruction of the maxillary central incisor, lateral incisor and canine was conducted with Mimics 20.0 software. The volumes of the roots were calculated using Gomagics Studio 12.0 software. The differences between the pre-treatment and post-treatment root volumes were statistically evaluated with a paired-samples t-test.
\end{abstract}

Results: There was no statistically significant difference in root resorption degree between the two kinds of torque brackets. The patient's degree of root resorption in the high torque self-ligating group was greater than that in the standard torque group.

Conclusions: There was no significant difference in root external apical resorption between the high torque selfligating brackets and the standard torque self-ligating brackets in bimaxillary protrusion patients.

Keywords: Self-ligating brackets, Torque, Root resorption

\section{Background}

Root resorption is one of the frequent complications of orthodontics. The prevalence of root resorption varies from 20 to $100 \%$ among orthodontic patients [1]. It has also been of great concern to orthodontic doctors in

\footnotetext{
*Correspondence: Ihyykqzxj@163.com; lililiuyi@163.com

${ }^{1}$ Department of Oral, Beijing Luhe Hospital, Capital Medical University, 82 Xinhua South Road, Beijing 101100, People's Republic of China

${ }^{3}$ Laboratory of Tissue Regeneration and Immunology and Department of Periodontics, Beijing Key Laboratory of Tooth Regeneration and Function Reconstruction, School of Stomatology, Capital Medical University, Tian Tan Xi Li No.4, Beijing 100050, People's Republic of China Full list of author information is available at the end of the article
}

recent years. Orthodontic root resorption involves external apical root resorption (EARR) (common in the tip of the root), which is the pathological process associated with cementum and dentin loss. The factors affecting root resorption include genetics, ethnicity, sex, age, the type of malocclusion, treatment time, the type of brackets, the direction and the magnitude of force, premolar extractions or not, and amount of apical displacement, which are all risk factors for EARR [2-6]. There has been a large amount of research on root resorption in recent years. In terms of appliances, the impact of root resorption has been reported, such as edgewise appliances, 
Begg techniques, and invisible appliances [7-10]. The effect of self-ligating brackets and conventional brackets on root resorption has been reported [11-13]. However, there are no prior reports on the effect of torque self-ligating brackets on root resorption. A number of previous studies on root resorption was performed using conventional radiographs, such as periapical and panoramic radiographs. These images are two-dimensional. However, root resorption changes in three-dimensional. The Two-dimensional (2D) images cannot detect root resorption on every surface. In addition, due to the magnification errors, geometric distortion and superposition they were not accurate to evaluate the amount of resorptionhave. Therefore the $2 \mathrm{D}$ images have some limitations in the accuracy of EARR measurement. CBCT is more gigantic advantages in the accuracy for odiagnosis and measurement of root resorption [14]. As an effective imaging method, CBCT is used to diagnose orthodontic root resorption. It is increasingly being used in the study of root resorption. CBCT was used to three-dimensional reconstruction with no the structural superimposition [15]. We can observe the images at all angles by using Three-dimensional (3D) reconstruction. Root resorption actually occurs in three dimensions, including on the buccal-lingual and mesial-distal sides, and the degree of absorption of each surface is different. Therefore, the volume index is more accurate than the length index in reflecting the degree of root resorption. Wang [16] has proved this point.

In view of the above, the aim of this study was to explore the different effects of root resorption in patients with maxillary protrusion using different torque brackets. Furthermore, we analysed the effects of the distance of root tip movement and the treatment time on root resorption.

\section{Methods}

This study was designed as a retrospective study, and it was conducted according to the Declaration of Helsinki principles. The study protocol was approved by the Ethics Committee of Beijing Luhe Hospital, Capital Medical University (2018LH-KS-008). Written informed consent was obtained from each participants before participating in the study.

Based on a retrospective power analysis, a total of 28 patients were required to demonstrate a clinically meaningful difference in root resorption between the appliance systems, with a 0.05 significance level and a power of $80 \%$.

In this retrospective study, 214 participants were screened in the Department of Orthodontics, Beijing Luhe Hospital, Capital Medical University. A total of 172 participants were excluded because they did not meet the inclusion criteria. Finally, 32 patients were enrolled in this study. They were divided into two groups according to the different torque brackets: a high torque self-ligating bracket group with 16 patients (Damon 3, ORMCO, USA) and a standard torque self-ligating bracket group with 16 patients. For the bracket torque data, see Table 1.

\section{Inclusion and exclusion criteria Inclusion criteria}

1. Patients aged $18-30$ years

2. Light or moderate anterior crowding with bimaxillary protrusion

3. CBCT was performed before and after treatment

4. All teeth erupted pre-treatment, the teeth were healthy, the maxillary incisors were without pulp disease and periapical disease, and there was no obvious root resorption

5. Extracted the four first premolars and implanted mini-screw implants

\section{Exclusion criteria}

1. Severe anterior crowding

2. Impacted teeth

3. Treatment of patients with anterior tooth trauma

4. Patients with hypoplasia

5. Patients who required orthognathic surgery or had already had surgery

6. Treatment with a conventional edgewise appliance

7. Did not receive extraction treatment

\section{Treatment procedure}

All 32 patients were treated with fixed orthodontic treatment, and the 4 first premolars were removed before treatment. The archwire sequence was 0.014 -in, $0.014 \times 0.025$-in, $0.019 \times 0.025$-in copper-nickel-titanium Damon (Ormco) and finished with $0.019 \times 0.025$-in stainless steel. The first and second premolars of the upper and lower jaws were implanted with planting nails. Miniscrews (Ningbo Cibei Medical Treatment Appliance Co., Ltd., China; diameter: $1.6 \mathrm{~mm}$; implant length: $11 \mathrm{~mm}$; screw length: $7 \mathrm{~mm}$ ) were placed between the second

Table 1 The bracket torque data of the two groups

\begin{tabular}{lccc}
\hline & $\begin{array}{l}\text { Maxillary } \\
\text { central } \\
\text { incisor }\end{array}$ & $\begin{array}{l}\text { Maxillary } \\
\text { lateral incisor }\end{array}$ & $\begin{array}{l}\text { Maxillary } \\
\text { canine }\end{array}$ \\
\hline High torque brackets & $11^{\circ}$ & $13^{\circ}$ & $22^{\circ}$ \\
Standard torque brackets & $7^{\circ}$ & $6^{\circ}$ & $15^{\circ}$ \\
\hline
\end{tabular}




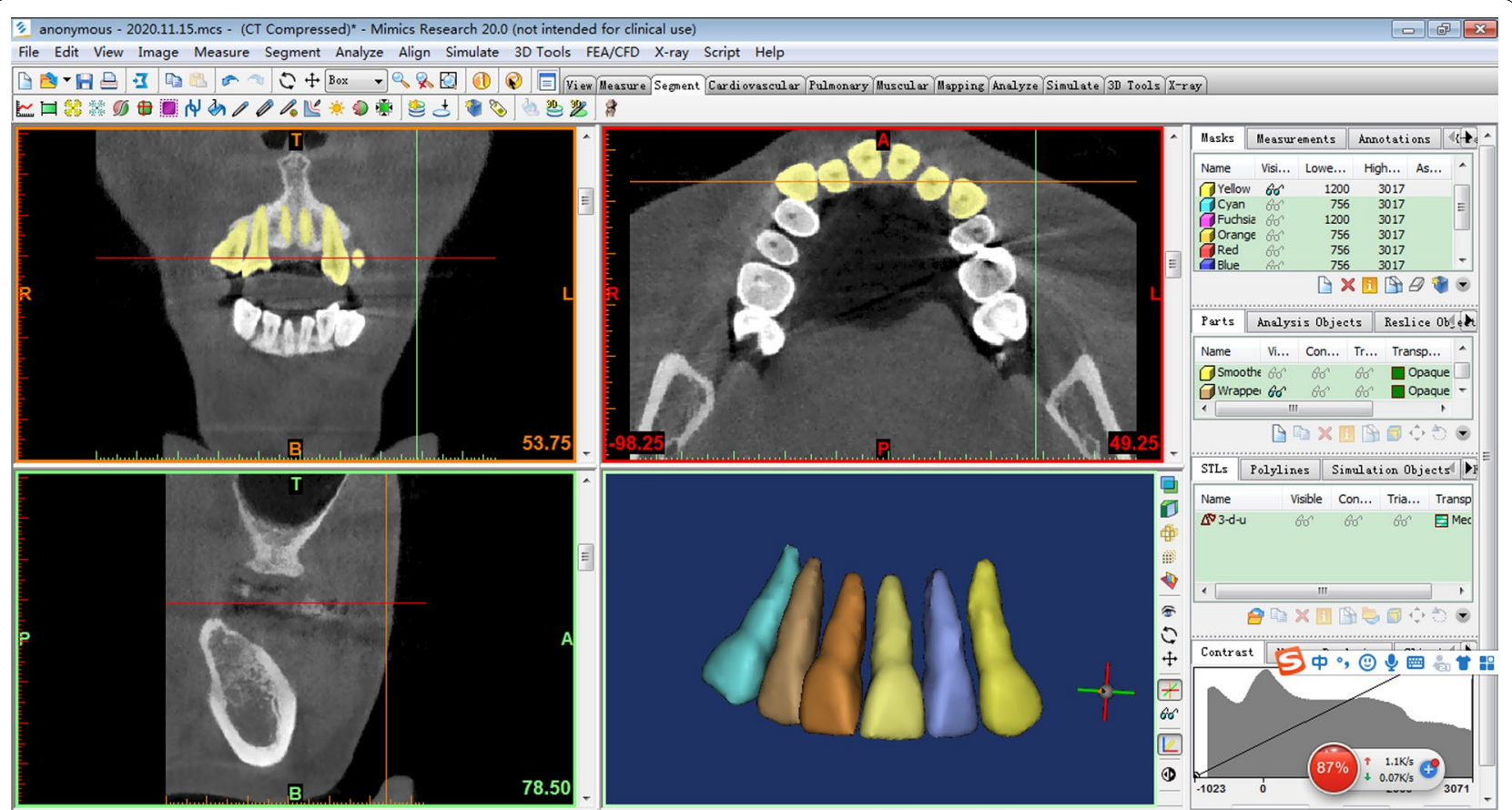

Fig. 1 Three-dimensional reconstruction

premolar and the first molar buccal to close the extraction space. The treatment completion time ranged from 20 to 32 months, with an average of 27.9 months. All patients were examined with the same $\mathrm{CBCT}$ machine (Planmeca Romexis, Finland; 0.2-mm voxel size, $90 \mathrm{kV}$, $8.0 \mathrm{~mA}, 13.755 \mathrm{~s}$ exposure time, and $351 \times 351 \times 410$ exposure field) and were operated on by the same dentist.

\section{Method of measurement}

Measurement of tooth volume: the CBCT data of the patients were imported into Mimics 20.0 software (Materialise, Leuven, Belgium), selecting the appropriate threshold for a single tooth reconstruction. The reconstructed teeth were exported to an STL file. Then, the STL file was imported into Gomagics Studio 12.0 (Materialise) for volume calculations (Figs. 1, 2).

\section{Error study}

The measurements were performed by the same imaging specialist. After 20 days of measurement, 10 randomly selected images were repeated for three-dimensional reconstruction and measurement. The measurement error was calculated by intraclass correlation coefficient (ICC) statistics. We calculated the intra-examiner consistency. According to Roberts and Richmond [17], the reliability is excellent if the ICC value is higher than 0.75 , acceptable if it is between 0.4 and 0.75 , and low if the ICC is smaller than 0.4. In this study, the ICC showed excellent intra-examiner reliability. The ICC for volume measurements showed an average of $95.7 \%$, with a range from 0.875 to 0.984 , and the method presented high reproducibility.

\section{Statistical analyses}

A paired $\mathrm{t}$-test was conducted to compare the degree of root resorption in each group before and after treatment. A unpaired t-test was used to assess the differences between groups. All of the data are expressed as the means with standard deviations, and the significance level was set at $5 \%$. Statistical calculations were performed with SPSS 20.0 (IBM Inc., USA).

\section{Results}

ICC statistics showed that there was almost perfect consistency between the two measures of root resorption upon the inspector evaluation. There were no statistically significant systematic errors. The casual errors were within the acceptable ranges.

There was no statistically significant difference in the comparison of the initial ages or the treatment time between the high torque group and the standard torque group (Table 2).

In the comparison between the two groups, there was a significant difference in all tooth volumes before and after treatment between the two groups (Tables 3 and 4). 


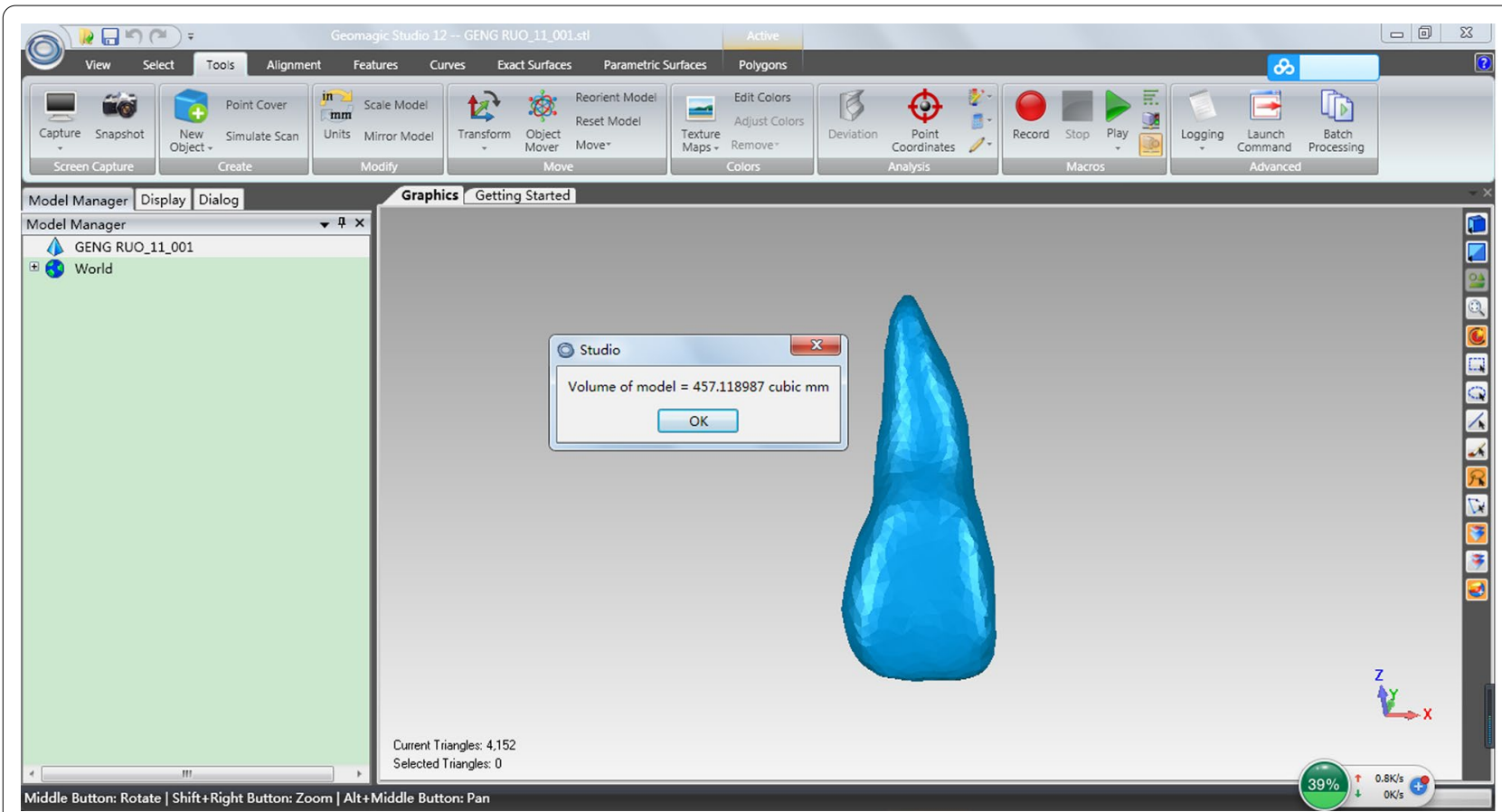

Fig. 2 Volume calculation

Table 2 Comparison of initial ages and treatment time between the high torque group and the standard torque group

\begin{tabular}{llllllll}
\hline Variable & \multicolumn{2}{l}{$\begin{array}{l}\text { High torque } \\
\text { group }\end{array}$} & & \multicolumn{2}{l}{$\begin{array}{l}\text { Standard } \\
\text { torque group }\end{array}$} & $P$ \\
\cline { 2 - 3 } & Mean & SD & & Mean & SD & \\
\hline Initial age (years) & 24.23 & 4.76 & & 24.71 & 5.46 & 0.486 \\
Treatment time (months) & 26.9 & 3.72 & & 25.32 & 4.60 & 0.206 \\
\hline
\end{tabular}

Table 3 The degree of root resorption $\left(\mathrm{mm}^{3}\right)$ between pretreatment and post-treatment for the patients with high torque

\begin{tabular}{llllll}
\hline Measurements $\left(\mathbf{m m}^{\mathbf{3}}\right)$ & Mean & SD & Mean & SD & $\boldsymbol{P}$ \\
\hline Maxillary right central incisor & 479.47 & 36.51 & 454.98 & 38.02 & 0.000 \\
Maxillary right lateral incisor & 336.24 & 24.43 & 314.84 & 21.52 & 0.000 \\
Maxillary right canine & 521.59 & 52.84 & 498.64 & 50.99 & 0.000 \\
Maxillary left central incisor & 480.41 & 33.81 & 455.35 & 32.56 & 0.000 \\
Maxillary left lateral incisor & 341.75 & 24.34 & 320.21 & 20.83 & 0.000 \\
Maxillary left canine & 514.59 & 52.84 & 490.91 & 49.96 & 0.000 \\
\hline
\end{tabular}

Root resorption occurred, and there was a significant difference after treatment in the two groups.

Although the root resorption of the high torque group was higher than that of the standard torque group, there
Table 4 The degree of root resorption $\left(\mathrm{mm}^{3}\right)$ between pretreatment and post-treatment for the patients in the standard torque group

\begin{tabular}{|c|c|c|c|c|c|}
\hline \multirow[t]{2}{*}{ Measurements $\left(\mathrm{mm}^{3}\right)$} & \multicolumn{2}{|c|}{$\begin{array}{l}\text { Pre-treatment } \\
\text { (T2) }\end{array}$} & \multicolumn{2}{|c|}{$\begin{array}{l}\text { Post- } \\
\text { treatment (T2) }\end{array}$} & \multirow[t]{2}{*}{$P$} \\
\hline & Mean & SD & Mean & SD & \\
\hline Maxillary right central incisor & 482.47 & 36.52 & 460.81 & 34.28 & 0.000 \\
\hline Maxillary right lateral incisor & 338.55 & 24.34 & 318.99 & 23.83 & 0.000 \\
\hline Maxillary right canine & 517.09 & 52.84 & 497.36 & 48.39 & 0.000 \\
\hline Maxillary left central incisor & 483.22 & 33.81 & 461.12 & 32.04 & 0.000 \\
\hline Maxillary left lateral incisor & 339.18 & 24.12 & 319.98 & 23.54 & 0.000 \\
\hline Maxillary left canine & 516.58 & 52.42 & 494.89 & 49.51 & 0.000 \\
\hline
\end{tabular}

was no statistically significant difference in the degree of root resorption (Table 5). After the treatment, the two groups of teeth had different root resorptions of the same teeth. However, there was no statistically significant difference.

\section{Discussion}

Root resorption is one of the common complications of orthodontics, and it is also the focus of orthodontic clinical research. Previous studies have shown that the degree of root resorption is lower in patients treated with selfligating brackets than in those treated with traditional 
Table 5 The difference in root resorption between the high torque and standard torque groups

\begin{tabular}{lllllll}
\hline Measurements $\left(\mathbf{m m}^{\mathbf{3}}\right)$ & $\begin{array}{l}\text { High torque } \\
\text { group (T1) }\end{array}$ & $\begin{array}{l}\text { Standard } \\
\text { torque group } \\
\text { (T2) }\end{array}$ & $P$ \\
\cline { 2 - 3 } & Mean & SD & & Mean & SD & \\
\hline Maxillary right central incisor & 24.48 & 6.31 & & 21.66 & 3.75 & 0.135 \\
Maxillary right lateral incisor & 21.41 & 4.1 & 19.57 & 2.41 & 0.133 \\
Maxillary right canine & 22.95 & 5.4 & 19.73 & 5.33 & 0.100 \\
Maxillary left central incisor & 25.07 & 4.52 & 22.09 & 4.54 & 0.073 \\
Maxillary left lateral incisor & 21.54 & 5.65 & 19.20 & 4.14 & 0.191 \\
Maxillary left canine & 23.48 & 5.69 & 21.69 & 6.11 & 0.398 \\
\hline
\end{tabular}

brackets [18]. Many studies have shown that there is no difference in root resorption between self-ligating brackets and traditional brackets [19-21]. However, the selfligating bracket has many advantages, such as a light force and a low friction force. They can reduce the operating time in the chair and bring comfort to the patients. They are widely used in orthodontics. With the development of self-ligating brackets, brackets with different torque angles have been introduced to meet the needs of clinical treatment. This experiment was designed to detect the effect of high torque brackets and standard torque brackets on root resorption in bimaxillary protrusion patients.

With the wide application of $\mathrm{CBCT}$, an increasing number of studies have been performed to evaluate root resorption by CBCT [22-24]. CBCT can accurately measure tooth and root resorption volumes, and it is a more accurate and reliable 3D measuring method for root resorption [19]. CBCT measures root resorption more often than on X-rays [25]. At present, most of the research on root resorption relies on length measurements. However, root resorption is not just a twodimensional variation in length. It includes changes in the three-dimensional direction of the buccal tongue and the proximal middle, and the absorption on each side is slightly different. Therefore, taking the volume of the tooth used to describe the amount of root absorption is more appropriate. It can more accurately reflect root resorption [26-29]. However, research in this area is still relatively limited. To better assess the degree of root resorption, this study also used the method of measuring the tooth volume to measure the degree of root resorption before and after treatment.

Patients with extracted teeth are more likely to develop root resorption than those who do not receive orthodontics [30-32]. In this study, all of the patients had the first premolar removed before treatment. The same orthodontist provided the same treatment, including a similar arch wire replacement throughout the entire treatment process. Mini-screw implants were inserted into the buccal region between the second premolar and first molar.

Excessive force is one of the factors involved in severe root resorption [33]. In this study, to avoid excessive force causing root resorption, $150 \mathrm{~g}$ of force was applied to retract the upper and lower anterior teeth to close the extraction space on each side [34]. All of the patients underwent $\mathrm{CBCT}$ by the same radiologist under the same parameters before and after treatment, which ensured good comparability between the two groups. In addition, we selected more patients $(32,192$ teeth) to reduce the study error caused by a small sample size.

In this study, we only considered the maxillary anterior teeth. On the one hand, the torque of the brackets in the two groups was different for the maxillary anterior teeth. On the other hand, the maxillary anterior teeth are the most prone to root resorption in orthodontic treatment [35-37]. Although the torque on the mandibular teeth was different from the standard torque, it was not included in this study. For patients with bimaxillary protrusion, a large number of anterior teeth were moved to improve the degree of protrusion [38]. Therefore, it is necessary to control the torque of the anterior teeth to acquire the desired tooth position [39]. The maxillary anterior teeth show the movement tendency of the coronal lip and the root tongue when using the high torque bracket, which is helpful to prevent torque loss in the anterior teeth. The stress expression value of the perimembrane in the high torque bracket was obviously higher than that of the standard torque bracket [40]. Case et al. [41] reported that the effect of torque force on root resorption showed that the greater the force, the greater the root resorption scope.

In this study, the average root absorption of the high torque bracket group and the standard torque bracket group were $23.15 \mathrm{~mm}^{3}$ and $20.34 \mathrm{~mm}^{3}$, respectively. Compared with the standard torque bracket, the root resorption of the high torque self-ligating bracket was slightly higher than that of the standard torque bracket. However, the difference between them was not statistically significant. In the relatively severe root resorption between the two groups, the number and quantity of moderate and severe root resorption in the high torque group were both greater than those in the standard torque group. Yangxue et al. [42] also showed that more torque control in the maxillary anterior teeth of the high torque group led to overall and partial root control and higher root resorption.

In this study, we found that there was no statistically significant difference in the treatment time between the groups. However, a longer treatment time led to more root resorption, which is consistent with previous 
studies $[20,43,44]$. Treatment duration is a risk factor for the development of severe EARR. However, some authors disagree $[2,45]$.

Some of the shortcomings of this study need attention. First, although we strictly matched the treatment group and the control group when choosing the cases, it may be difficult to avoid the effects of confounding factors on the results. It is best to compare the root resorption of the two types of brackets by random selection in the future. Second, although the detection process has increased the sample size compared with previous studies, the sample size is still insufficient. In future studies, we will continue to increase the sample size to correct for the effect of the sample size on the results. Finally, we still need to include more patients of different races to verify whether the two brackets affect root resorption.

\section{Conclusion}

There was no significant difference in external apical root resorption between patients treated with the high torque Damon self-ligating bracket and the high torque Damon self-ligating bracket.

\section{Abbreviations \\ EARR: External apical root resorption; CBCT: Cone beam computed tomog- raphy; ICC: Intraclass correlation coefficient; 2D: Two-dimensional; 3D: Three-dimensional.}

\section{Acknowledgements}

This work was supported by the Capital Medical University.

\section{Authors' contributions}

$\mathrm{HZ}$ and $\mathrm{XZ}$ designed the study, gathered the information, performed the statistical analysis and wrote the first draft of the manuscript. $X \mathrm{~L}$ checked the language and assisted with the statistical analysis. YL critically revised and edited the manuscrip. All authors read and approved the final manuscript.

\section{Funding}

This study was supported by Capital Medical University Nature Cultivation Fund (Code: PYZ2017003) (supporting the research and manuscript preparation)

\section{Availability of data and materials}

The datasets used and/or analyzed during this study belongs to the authors and are available from the corresponding author only upon on reasonable request.

\section{Declarations}

Ethics approval and consent to participate

All research procedures were approved by the ethics committee of Beijing Luhe Hospital, Capital Medical University(2018LH-KS-008).The participants were informed about the study in written and verbally, and about voluntariness. All participants gave their signed informed consent.

\section{Consent for publication}

Not applicable.

\section{Competing interests}

The authors declare that they have no competing interests.

\section{Author details}

${ }^{1}$ Department of Oral, Beijing Luhe Hospital, Capital Medical University, 82 Xinhua South Road, Beijing 101100, People's Republic of China. ${ }^{2}$ Department of Radiology, Beijing Luhe Hospital, Capital Medical University, Beijing 101100, People's Republic of China. ${ }^{3}$ Laboratory of Tissue Regeneration and Immunology and Department of Periodontics, Beijing Key Laboratory of Tooth Regeneration and Function Reconstruction, School of Stomatology, Capital Medical University, Tian Tan Xi Li No.4, Beijing 100050, People's Republic of China.

Received: 19 October 2021 Accepted: 4 January 2022

Published online: 11 January 2022

\section{References}

1. Baumrind S, Korn EL, Boyd RL. Apical root resorption in orthodontically treated adults. Am J Orthod Dentofac Orthop. 1996;110(3):311-20.

2. Al-Qawasmi RA, Hartsfield JK Jr, Everett ET, Flury L, Liu L, Foroud TM, Macri JV, Roberts WE. Genetic predisposition to external apical root resorption. Am J Orthod Dentofac Orthop. 2003;123(3):242-52.

3. Acar A, Canyürek U, Kocaaga M, Erverdi N. Continuous vs. discontinuous force application and root resorption. Angle Orthod. 1999;69(2):159-63 (discussion 163-4).

4. Levander $\mathrm{E}$, Malmgren $\mathrm{O}$. Evaluation of the risk of root resorption during orthodontic treatment: a study of upper incisors. Eur J Orthod. 1988;10:30-8.

5. Weltman B, Vig KW, Fields HW, Shanker S, Kaizar EE. Root resorption associated with orthodontic tooth movement a systematic. Am J Orthod Dentofac Orthop. 2010;137(4):462-76.

6. Roscoe MG, Meira JB, Cattaneo PM. Association of orthodontic force system and root resorption: a systematic review. Am J Orthod Dentofac Orthop. 2015;147:610-26.

7. Janson GR, De Luca CG, Martins DR, Henriques JF, De Freitas MR. A radiographic comparison of apical root resorption after orthodontic treatment with 3 different fixed appliance techniques. Am J Orthod Dentofac Orthop. 1999;118:262-73.

8. Mavragani M, Vergari A, Selliseth NJ, Boe OE, Wisth PJ. A radiographic comparison of apical root resorption after orthodontic treatment with a standard edgewise and a straight-wire edgewise technique. Eur J Orthod. 2000;22:665-74.

9. Beck BW, Harris EF. Apical root resorption in orthodontically treated subjects: analysis of edgewise and light wire mechanics. Am J Orthod Dentofac Orthop. 1994;105:350-61.

10. Zhang Z, Liu Y. Root resorption during orthodontic treatment with aligners. Chin J Orthod. 2018;25(4):191-5.

11. Leite V, Conti AC, Navarro R, Almeida M, Oltramari-Navarro P, Almeida R. Comparison of root resorption between self-ligating and conventional preadjusted brackets using cone beam computed tomography. Angle Orthod. 2012;82:1078-82.

12. Liu $X Q$, Sun $X L$, Yang $Q$, Fan $C H$, Chen XJ. Comparative study on the apical root resorption between self-ligating and conventional brackets in extraction patients. Shanghai Kou Qiang Yi Xue. 2012;21(4):460-5.

13. Chen W, Haq AA, Zhou Y. Root resorption of self-ligating and conventional preadjusted brackets in severe anterior crowding class I patients: a longitudinal retrospective study. BMC Oral Health. 2015;15:115.

14. Yi J, Sun Y, Li Y, Li C, Li X, Zhao Z. Cone-beam computed tomography versus periapical radiograph for diagnosing external root resorption: a systematic review and meta-analysis. Angle Orthod. 2017;87(2):328-37.

15. Ahn HW, Moon SC, Baek SH. Morphometric evaluation of changes in the alveolar bone and roots of the maxillary anterior teeth before and after en masse retraction using cone-beam computed tomography. Angle Orthod. 2013;83:212-21.

16. Wang Y, He S, Guo Y, Wang S, Chen S. Accuracy of volumetric measurement of simulated root resorption lacunas based on cone beam computed tomography. Orthod Craniofac Res. 2013;16:169-76.

17. Roberts CT, Richmond S. The design and analysis of reliability studies for the use of epidemiological and audit indices in orthodontics. $\mathrm{Br} J$ Orthod. 1997;24(2):139-47. 
18. Liu Y, Guo HM. Comparison of root resorption between self-ligating and conventional brackets using cone-beam CT. Shanghai Kou Qiang Yi Xue. 2016;25(2):238-41.

19. Handem $\mathrm{RH}$, Janson $\mathrm{G}$, Matias $\mathrm{M}$, et al. External root resorption with the self-ligating Damon system - a retrospective study. Prog Orthod. 2016;17(1):20

20. Qin F, Zhou Y. The influence of bracket type on the external apical root resorption in class I extraction patients - a retrospective study. BMC Oral Health. 2019;19(1):53.

21. Jacobs C, Gebhardt PF, Jacobs V, Hechtner M, Meila D, Wehrbein $H$. Root resorption, treatment time and extraction rate during orthodontic treatment with self-ligating and conventional brackets. Head Face Med. 2014;10:160X-X210.

22. Xu SD. Explore the evaluation of adult orthodontic treatment of root resorption with CBCT. Gen J Stomatol. 2015;2:98-9.

23. Wang F, Wang JG, Zhang XZ. Examining incisor root resorption using CBCT after orthodontic treatment for adults with skeletal class III malocclusion. Tianjin Med J. 2015;43:390-3.

24. Ni M, Lei Y, Chen WJ, Wu GR. Cone beam computed tomography study on the apical root resorption after orthodontic treatment in root-filled teeth. Stomatologie. 2016;36:233-6.

25. Rischen RJ, Breuning KH, Bronkhorst EM, Kuijpers-Jagtman AM. Records needed for orthodontic diagnosis and treatment planning: a systematic review. PLoS ONE. 2013;8:e74186.

26. Sun BY, Wang $L$, Deng RX, Ding Y. Comparative evaluation of root resorption in mandibular incisors following the treatment of adults with skeletal class III. Prog Mod Biomed. 2012;12:1098-100.

27. Li W, Chen F, Zhang F, Ding W, Ye Q, Shi J, Fu B. Volumetric measurement of root resorption following molar mini-screw implant intrusion using cone beam computed tomography. PLoS ONE. 2013;8(4):e60962.

28. Zhang RF, Wang HM, Bai YX, Li S. Effects of orthodontic force on upper central incisor's developing roots. Beijing Kou Qiang Yi Xue. 2016:24:335-7.

29. Aras I, Unal I, Huniler G, Aras A. Root resorption due to orthodontic treatment using self-ligating and conventional brackets: a cone-beam computed tomography study. J Orofac Orthop. 2018;79:181-90.

30. Iglesias-Linaresa A, Sonnenbergb B, Solanob B, Yañez-Vico R-M, Solanod E, Lindauere SJ, Flores-Mir C. Orthodontically induced external apical root resorption in patients treated with fixed appliances vs removable aligners. Angle Orthod. 2017:87:3-10.

31. Marcio RA, Aline SB, Thais MF, Juliana BV, Renato R, Ravindra N. A comparative study of the effect of the intrusion arch and straight wire mechanics on incisor rootresorption: a randomized, controlled trial. Angle Orthod. 2018;88:20-6

32. Carlos EN, Andreia CF, Ana C, Danilo PV, Mauricio AC, Renata Rodrigues AP. Comparative study of root resorption of maxillary incisors in patients treated with lingual and buccal orthodontics. Angle Orthod. 2017;87:795-800

33. Weltman B, Vig KW, Fields HW, Shanker S, Kaizar EE. Root resorption associated with orthodontic tooth movement: a systematic review. Am J Orthod Dentofac Orthop. 2010;137:462-76.

34. Lu Y, Zeng X, Gao X. Comparison of the friction resistance in sliding mechanics at different forces level for space closing - a nonlinear finite element study. Chin J Orthod. 2009;16(4):207-10.

35. Motokawa M, Sasamoto T, Kaku M, Kawata T, Matsuda Y, Terao A, Tanne K. Association between root resorption incident to orthodontic treatment and treatment factors. Eur J Orthod. 2012;34(3):350-6.

36. Maués $C P$, do Nascimento RR, Vilella Ode V. Severe root resorption resulting from orthodontic treatment: prevalence and risk factors. Dent Press J Orthod. 2015;20(1):52-8.

37. Jung $\mathrm{YH}, \mathrm{Cho} \mathrm{BH}$. External root resorption after orthodontic treatment: a study of contributing factors. Imaging Sci Dent. 2011;41:17-21.

38. Lu H, Fu M. Clinical study of adductive maxillary incisor with square wire arch correction technique. Orthodontics. 1995;4(2):145-8.

39. Bai D, Gu M, Zhang J. Incisor torque control with fixed appliance. Zhonghua Kou Qiang Yi Xue Za Zhi. 2004;39(2):104-7.

40. Xing B, Wang Y, Feng F, et al. Three-dimensional finite element analysis of the effect of brackets torque on the process of mass retraction of maxillary anterior teeth. Stomatology. 2018;38(5):440-4.
41. Case MA, Faltin RM, Faltin K, et al. Root resorptions in upper pre- molar after application of continuous torque moment, intra individual study. J Orofac Orthop. 2001;62(4):285-95

42. Yang X, Qian YF. Torque control evaluated by lateral cephalometric radiography and cone-beam CT after retraction of the upper anterior teeth. Shanghai Kou Qiang Yi Xue. 2016;25(4):469-74.

43. Makedonas D, Lund H, Gröndahl K, Hansen K. Root resorption diagnosed with cone beam computed tomography after 6 months of orthodontic treatment with fixed appliance and the relation to risk factors. Angle Orthod. 2012;82(2):196-201.

44. Smale I, Artun J, Behbehani F, Doppel D, Van't Hof M, Kuijpers-Jagtman AM. Apical root resorption 6 months after initiation of fixed orthodontic appliance therapy. Am J Orthod Dentofac Orthop. 2005;128:57-67.

45. Artun J, Van't Hullenaar R, Doppel D, Kuijpers-Jagtman AM. Identification of orthodontic patients at risk of severe apical root resorption. Am J Orthod Dentofac Orthop. 2009;135(4):448-55.

\section{Publisher's Note}

Springer Nature remains neutral with regard to jurisdictional claims in published maps and institutional affiliations.
Ready to submit your research? Choose BMC and benefit from:

- fast, convenient online submission

- thorough peer review by experienced researchers in your field

- rapid publication on acceptance

- support for research data, including large and complex data types

- gold Open Access which fosters wider collaboration and increased citations

- maximum visibility for your research: over $100 \mathrm{M}$ website views per year

At BMC, research is always in progress.

Learn more biomedcentral.com/submissions 